Discussion Paper No. 1034

\title{
HIGHER ORDER RISK ATTITUDES AND PREVENTION UNDER DIFFERENT TIMINGS OF LOSS
}

\author{
Takehito Masuda \\ Eungik Lee
}

June 2018

The Institute of Social and Economic Research Osaka University

6-1 Mihogaoka, Ibaraki, Osaka 567-0047, Japan 
Higher order risk attitudes and prevention under different timings of loss

$$
\text { Takehito Masuda }{ }^{1,2} \text { and Eungik Lee }{ }^{3}
$$

June 25, 2018

\begin{abstract}
This paper provides experimental evidence of the role of higher order risk attitudes - especially prudence - in prevention behavior. Prudence, under an expected utility framework, increases (decreases) self-protection effort compared to the risk neutral level when the risk of losing part of an income exists in a future (the same) period. Motivated by these predictions that give the exact test on prudence, an experiment was designed where subjects go through higher order risk attitude elicitation and make a self-protection decision. In contrast to expected utility theory, the observed efforts are less than the risk neutral level, regardless of the timing of loss. This violation of expected utility predictions could be explained by probability weighting.
\end{abstract}

Keywords: Higher order risk attitudes; Prudence; Prevention; Timing of loss; Probability weighting

JEL classification: C91, C92, D81, E21

\title{
1. Introduction
}

Intertemporal choice under risk dates back to Leland's (1968) analysis of precautionary saving.

\footnotetext{
${ }^{1}$ Institute of Social and Economic Research, Osaka University, Mihogaoka 6-1, Ibaraki, Osaka 567-0047 Japan

2 Corresponding Author. E-mail: tmasuda@iser.osaka-u.ac.jp Phone: +81-6-6879-8581 OCRID: 00000001-9639-2480

${ }^{3}$ Department of Economics, Seoul National University Gwanak-ro 1, Gwanak-gu Seoul, South Korea
} 
Kimball (1990) found that willingness to save more under a greater background risk, called prudence, is equivalent to a positive third derivative of the utility function under the expected utility framework. Subsequent to this seminal work, the concept of higher order risk attitudes, including prudence, has also been widely applied to non-financial contexts. Gollier et al. (2000) showed that the intensity of prudence is an important factor in the optimal investment in new technology, such as genetically-modified food, when potential damage may be revealed in the future as scientific knowledge advances. White (2008) studied the role of prudence in a bargaining situation and showed that prudence plays a similar role as increasing a player's patience and, hence, improves the bargaining outcome. ${ }^{4}$

Recently, experimental investigation of higher order risk attitudes has emerged. Eeckhoudt and Schlesinger (2006) developed a model-free method of eliciting higher order risk attitudes called risk apportionment tasks. Since then, much research has been done to find empirical evidence of higher order risk attitudes (Deck and Schlesinger 2010, 2014; Ebert and Wiesen 2011, 2014; Noussair et al. 2014; Haering et al. 2017; Bleichrodt and Bruggen 2018; Heinrich and Mayrhofer 2018). These studies commonly find that subjects are highly prudent, and the findings are robust to various experimental designs, such as stake size, asymmetric zero-mean risks, and reduced lottery structures (Trautmann and van de Kuilen, 2018). Among many important findings, there are two from previous literature that are noteworthy. First, Noussair et al. (2014) find that prudent people are more likely to have a greater amount of savings. This result is one of the first empirical evidence that prudence could explain important aspects of financial decision. Second, Ebert and Wiesen (2014) find that measured downside risk premia are beyond the prediction of the expected utility model. This result implies that the expected utility model is not sufficient to empirically explain the high prudence of agents.

\footnotetext{
${ }^{4}$ See also Gollier et al. (2013) for a survey of higher order risk theory.
} 
This study is, to the best of our knowledge, the first attempt to experimentally test comparative statics between prudence and prevention behavior using different timings of loss in a self-protection context. ${ }^{5}$ The outcomes of prevention come at different points in time. For example, having safe driver education reduces the risk of future accidents, while paying attention to driving reduces the immediate risk of an accident. We introduce a prevention game in which a player can make an effort to reduce the probability of a loss. Theoretically, prudence is known to have different effects depending on the timing of loss. In particular, Menegatti (2009) (Eeckhoudt and Gollier, 2005) find that prudence increases (decreases) prevention effort when the loss may occur in the future (same) period, compared to a risk-neutral scenario. We test these different effects of prudence on prevention behavior using a lab experiment. Our test is parameter-free in the sense that predictions depend only on the assumption that a player is prudent.

In this experiment, the subjects participated in a higher order risk attitude task, prevention game, and time preference elicitation. We employed a between-subjects design, where each subject was assigned to one of two variants of the prevention game, depending on the timing of the loss (current loss or future loss).

The data systematically violate the expected utility predictions. We find that most subjects are highly (around 95\%) prudent, in line with previous literature. Based on the predictions of Eeckhoudt and Gollier (2005) and Menegatti (2009), we expect subjects facing a future loss to exert more effort than those facing a current loss. The results, however, show that subjects exert less effort than a risk-neutral player regardless of the timing of loss. When we analyze the withintreatment data, more prudent subjects make lower effort for prevention, regardless of the timing of the loss. This result is in line with Eeckhoudt and Gollier (2005), but contradictory to Menegatti

\footnotetext{
5 A few studies note how prudence affects behavior in experimental games (Kocher et al., 2015; Cardella and Kitchens, 2017; and Krieger and Mayrhofer, 2017).
} 
(2009).

Ebert and Wiesen (2014), Eeckhoudt et al. (2017), and Trautmann and van de Kuilen (2018) argue that expected utility models could be too narrow to describe higher order risk attitudes. We use probability weighting (Kahneman and Tversky, 1979; Tversky and Kahneman 1992; Wakker, 2010) as an alternative explanation for this conflicting observation. We establish that, in our design, players with Prelec (1998) probability weighting exert less effort than a risk-neutral player regardless of the timing of loss. Moreover, returning to a choice-based definition of prudence, we also show that probability weighting can result in prudent choices in our higher order risk attitude elicitation task.

The remainder of this paper is organized as follows. Section 2 presents the prevention game predictions of prevention game based on the expected utility model. Section 3 describes the experimental design and Section 4 discusses the main results. Section 5 examines how probability weighting can explain the data. Section 6 provides our concluding remarks.

\section{The Model}

\subsection{Prudence: downside risk aversion}

Let $(a, p ; b)$ with $a>b$ represent a simple lottery where a player can obtain $a$ with probability of $p$, and obtain $b$ with probability of 1-p. Consider two compound lotteries, $L$ and $R$, shown in Figure 1. Both lotteries have a simple lottery $(a, .5 ; b)$ in common, but differ in whether a zero-mean risk $\left(z_{1}, p ;-z_{2}\right)$ with $z_{1}, z_{2}>0$ is attached to a richer or a poorer state of the simple lottery. A player is prudent if she prefers $R$ to $L$ for any $a, b$ and zero-mean risk. In other words, prudence is equivalent to downside risk-aversion. It is known that, under the expected utility framework, prudence is equivalent to a convex marginal utility function. 


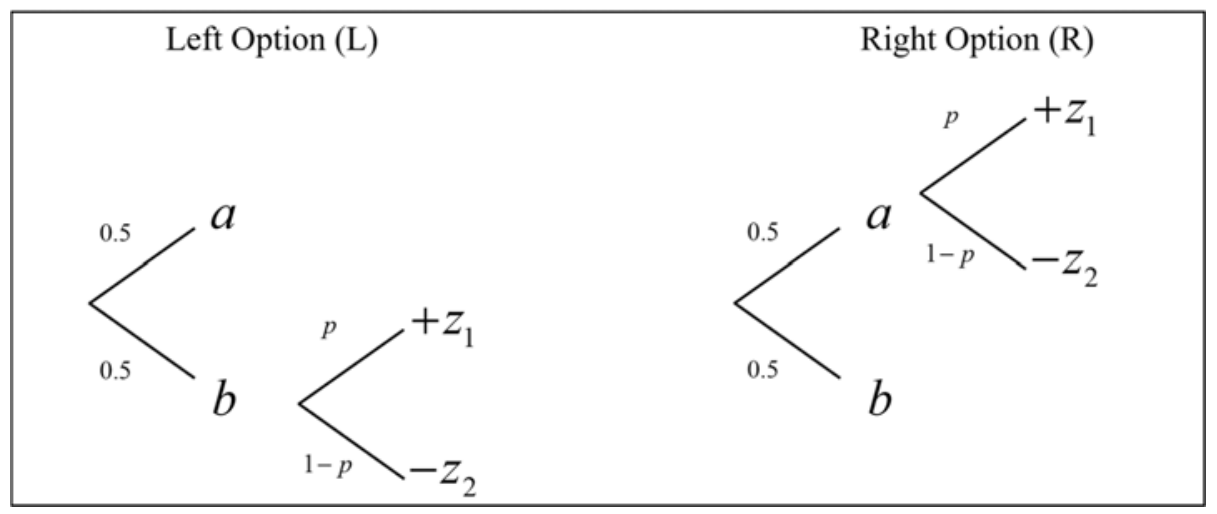

Fig. 1. Upside and downside risk

Definition 1 (Kimball, 1990). The player is prudent (imprudent) if $u^{\prime}$ is convex (concave).

Kimball (1990) showed that a prudent player increases his optimal saving to cope with uncertainty regarding future income. The logic is as follows. Suppose there are two periods, 1 and 2, where the player is endowed $w_{1}$ and $w_{2}$ respectively. Without uncertainty, the player chooses optimal saving

$$
s^{*} \in \arg \max u\left(w_{1}-s\right)+u\left(w_{2}+\rho s\right)
$$

where $\rho>1$, which represents the interest rate.

With uncertainty, we additionally assume zero-mean risk $\tilde{z}$ in future income. Then, the player's optimal saving is given by

$$
s * * \in \arg \max u\left(w_{1}-s\right)+\mathrm{E}\left[u\left(w_{2}+\rho s+\tilde{z}\right)\right] .
$$

Saving increases under risk $\left(s^{* *}>s^{*}\right)$ for any endowment and zero mean-risk, if and only if 
$\mathrm{E}\left[u^{\prime}(x+\tilde{z})\right] \geq u^{\prime}(x)$ for any $x$ and $\tilde{z}$. Therefore, the equivalent condition is convexity of $u^{\prime}{ }^{6}$ This similar logic can be applied in a prevention context, such as preparing for an impending loss. In the following two subsections, we introduce two different prevention games used to build our experimental design. The two games are similar but differ in the timing of the loss.

\subsection{Prevention game with a future loss}

There is a single player who lives for two periods, today and the future. Let $y$ and $z$ be the player's income today and in the future, respectively. The player faces endogenous uncertainty regarding the probability of losing $d$ out of $z$. The player chooses effort $e \in[0, \bar{e}]$ where $\bar{e}<y$, to reduce the probability of a future loss event. $p(e) \in[0,1]$ is the probability of a loss decreasing function on $e$ but the marginal effect of effort on loss probability is decreasing $\left(p^{\prime}(e)<0, p^{\prime \prime}(e)>0\right)$. The amount of effort, $e$, is used from today's income and is non-refundable. Then, in the future, the player faces a lottery $(z, 1-p(e) ; z-d)$. Figure 2-(a) illustrates the example time line of this situation, which is called a prevention game with a future loss.

(a) Future Loss

(b) Current Loss

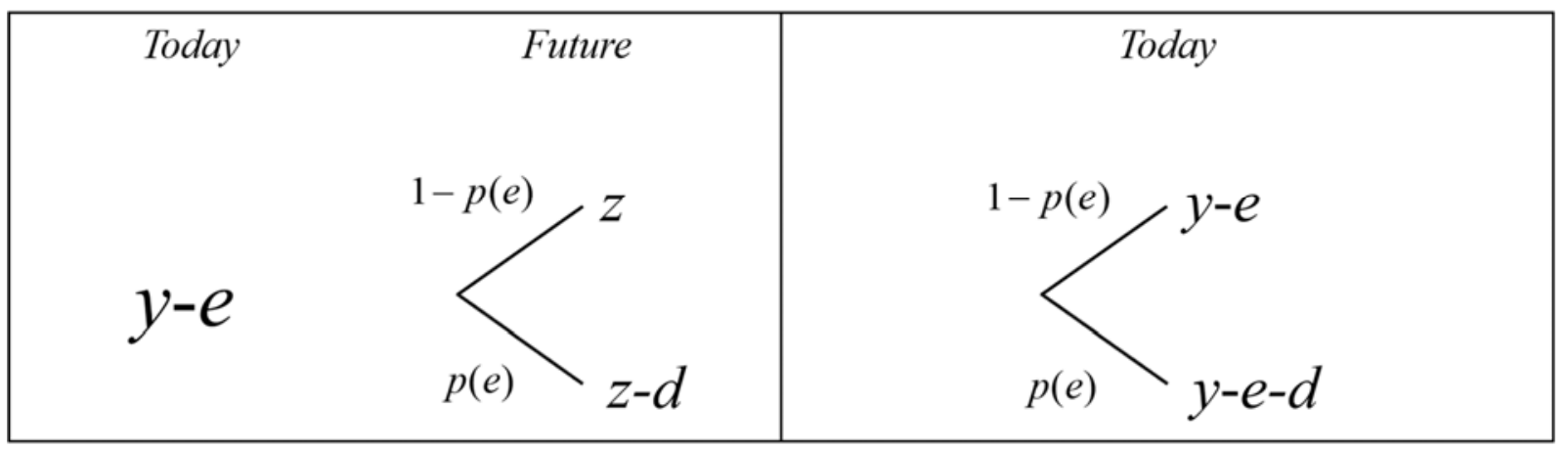

Fig. 2 Prevention game depending on the timing of the loss

\footnotetext{
${ }^{6}$ Gollier (2004) also explains this role of prudence in Chapter 16.
} 
Given the player's utility function $u$, we can formulate the player's problem as maximization of his/her expected utility:

$$
\max _{e \in[0, \bar{e}]} u(y-e)+p(e) u(z-d)+(1-p(e)) u(z) .
$$

We assume the objective function is concave. ${ }^{7}$ First, consider the risk-neutral case: $u(x)=x$. Then, (1) reduces to:

$$
\max _{e \in[0, \bar{e}]} y-e+p(e)(z-d)+(1-p(e)) z
$$

The first order condition is given by:

$$
-p^{\prime}(e) d=1
$$

Denote the solution of (3) by $e_{n}$. We follow Menegatti's (2009) assumption on $y$ and $z$ :

$$
y=z-p\left(e_{n}\right) d+e_{n}
$$

Proposition 1 (Menegatti 2009). Consider a prevention game with a future loss. Assume $p\left(e_{n}\right)=1 / 2$ and (4). If the player is prudent (imprudent), then, his/her optimal effort is higher (lower) than $e_{n}$.

The intuition behind this proposition is similar to Kimball (1990) in the previous section in the sense that a prudent player will reduce today's consumption in anticipation of a possible loss. Courbage et al. (2013) show that a prudent player prefers to accumulate expected wealth in the period in which she bears the risk.

\subsection{Prevention game with a current loss}

Interestingly, prudence has a negative impact on optimal effort in the situation where the loss event

7 The same assumption is made by Menegatti (2009) and Eeckhoudt and Gollier (2005). 
occurs in the same period as the effort. This situation is called a prevention game with a current loss, as illustrated by Figure 2-(b). There is only one period with today's income, $y$. Note that changes in loss timing and changes in wealth do not alter the risk neutral player's effort. and, hence, that player chooses the same amount of $e_{n}$ as in the future loss case. Consider a prudent player. Since the player bears the risk in the current period and the richer state outcome is decreasing in $e$, the player has an incentive to expend less effort than the risk-neutral player. Eeckhoudt and Gollier (2005) formalized this observation. In a game with a current loss, we can formulate the player's problem as maximization of his/her expected utility:

$$
\max _{e \in[0, \bar{e}]} p(e) u(y-e-d)+(1-p(e)) u(y-e) .
$$

We assume the objective function is concave. he negative effect of prudence on effort is summarized as follows.

Proposition 2 (Eeckhoudt and Gollier 2005). Consider a prevention game with a current loss. Assume $p\left(e_{n}\right)=1 / 2$. If the player is prudent (imprudent), then, his/her optimal effort is smaller (higher) than $e_{n}$

The intuition behind Proposition 2 is shown by the fact that prudence implies skewnessseeking (Ebert and Wiesen 2011). Consider the simple case where $y=11, e \in[0,3]$, and $p(e)=2 /(e+2)$. When effort is 1 , this induces a lottery $L_{1}=(10,1 / 3 ; 2)$, while when effort is 2 (risk neutral effort), the lottery induced is $L_{2}=(9,1 / 2 ; 1)$. Then, $L_{1}$ has skewness of $1 / \sqrt{2}$, while $L_{2}$ has skewness of zero. Thus, a prudent player prefers to make less effort than the risk neutral player. 


\section{Experimental Design}

We conducted identical processes of the experiment at Osaka University, Japan, and Seoul National University, South Korea. Subjects were recruited through the ORSEE recruiting system (Greiner, 2015). The experiment was computerized using the experimental software z-Tree (Fischbacher, 2007). Subjects were randomly seated at computer terminals, separated by partitions, and no communication was permitted between subjects. Each subject had a set of printed instructions (distributed for each part as the session proceeded) and a piece of paper for taking notes. There were three parts in each session. In each part, the experimenter read the instructions aloud. The experimenter explained how to operate the computer interface, which will be explained in a later part of this paper. Then, the subjects were given time to ask questions by raising their hands quietly.

Part 1 is a lottery task, intended to elicit higher order risk attitudes in line with Noussair et al. (2014).

Table 2. List of questions in Part 1

\begin{tabular}{lll}
\hline & Option L $^{\mathrm{a}}$ & Option R \\
\hline Aversion 1 & {$\left[650^{\mathrm{b}} 50\right]$} & 200 \\
Aversion 2 & {$\left[650 \_50\right]$} & 250 \\
Aversion 3 & {$\left[650 \_50\right]$} & 300 \\
Aversion 4 & {$\left[650 \_50\right]$} & 350 \\
Aversion 5 & {$\left[650 \_50\right]$} & 400 \\
Prudence 1 & {$\left[900 \_\left(600+\left[200 \_-200\right]\right)\right]$} & {$\left[900\left(+\left[200 \_-200\right]\right) \_600\right]$} \\
Prudence 2 & {$\left[1350 \_\left(900+\left[300 \_-300\right]\right)\right]$} & {$\left[1350\left(+\left[200 \_-200\right]\right) \_900\right]$} \\
Prudence 3 & {$\left[900 \_\left(600+\left[100 \_-100\right]\right)\right]$} & {$\left[900\left(+\left[100 \_-100\right]\right) \_600\right]$} \\
Prudence 4 & {$\left[650 \_\left(350+\left[200 \_-200\right]\right)\right]$} & {$\left[650\left(+\left[200 \_-200\right]\right) \_350\right]$}
\end{tabular}


Prudence 5 [900_(600+[400_-400])]

Prudence 6 [1100_(600+[400_-400])]

Prudence 7 [750_(300+[100_-100])]

Prudence $8 \quad$ [1000_(400+[300_-300])]

Prudence 9 [600_(350+[200_-200])]

Prudence 10 [800_(400+[300_-300])]

Temperance 1 [(900+[300_-300])_(900+[300_-300])]

Temperance 2 [(300+[100_-100])_(300+[100_-100])]

Temperance 3 [(900+[300_-300])_(900+[100_-100])]

Temperance 4 [(700+[300_-300])_(700+[300_-300])]

Temperance $5 \quad\left[\left(900+\left[300 \_-300\right]\right) \_\left(900+\left[500 \_-500\right]\right)\right]$
[900(+[400_-400])_600]

$\left[1100\left(+\left[400 \_-400\right]\right) 600\right]$

$\left[750\left(+\left[100 \_-100\right]\right) \_300\right]$

$\left[1000\left(+\left[300 \_-300\right]\right)+400\right]$

$\left[650\left(+\left[200 \_-200\right]\right) \_350\right]$

$\left[800\left(+\left[300 \_-300\right]\right) \_400\right]$

[900_(900+[300_-300]+[300_-300])]

[300_(300+[100_-100]+[100_-100])]

[900_(900+[300_-300]+[100_-100])]

$\left[700 \_\left(700+\left[300 \_-300\right]+\left[300 \_-300\right]\right)\right]$

[900_(900+[300_-300]+[500_-500])]

Notes. a) The positions of Option R and Option $\mathrm{L}$ are reversed in some sessions to balance the order effect.

b) Lotteries are in JPY value. Approximately $1 \mathrm{USD}=110 \mathrm{JPY}$ as of August 2017. We translated $1 \mathrm{JPY}$ as $10 \mathrm{KRW}$ for the sessions at Seoul National University.

There is not much empirical evidence about the correlation between higher order risk attitudes and prevention. Therefore, we elicited not only prudence but also risk aversion and temperance to control for the various higher order risk attitudes. Table 2 reports the list of lotteries used in Part 1. In Table 2, we use the notation [x_y], which indicates a lottery to receive either $\mathrm{x}$ (JPY) or $\mathrm{y}$ (JPY) with 0.5 probability, respectively. Compounding lotteries are represented using the + symbol in Table 2. In Part 1, 20 questions are grouped in three subparts to measure different aspects of higher order risk attitudes. The first subpart is comprised of five questions and measures the subjects' risk aversion. The second subpart is aimed at measuring the level of prudence using a compound lottery structure. Prudent subjects would assign zero-mean risk to high wealth rather than low wealth. The third subpart is to measure temperance using a three-dice structure. Temperate individuals are defined as those tending to allocate two zero-mean risks to different states. No feedback is given during Part 1. For the payment in Part 1, one of the 20 questions is 
randomly selected, and its payoff is realized at the end of the session.

In Part 2, the prevention game is composed of 15 rounds, including 5 initial practice rounds. In this part, we introduce Experimental Currency Units (ECUs) with the conversion rate of $1 \mathrm{ECU}=$ $2 \mathrm{JPY}^{8}$ In each round, subjects are exposed to potential loss from their endowment. They can choose an effort $e$ in integers from 0 to 300 (ECUs). In our experiment, we used:

$$
p(e)=\frac{200}{e+200},
$$

which simplifies the risk neutral effort level $\left(e_{n}\right)$ as 200 and loss size $(d)$ as $800 .{ }^{9}$

In the experiment, subjects are presented with a graph and table describing the probability of loss and effort. Figure 3 shows the screenshot of decision-making in Part 2. The participants use a slider and arrows that allows them to simultaneously check the possible outcomes and probability as they change their level of effort.

\footnotetext{
${ }^{8} 1 \mathrm{ECU}=20 \mathrm{KRW}$ in the Seoul National University sessions.

9 Through the comparative statics presented in Section 2 (Propositions 1 and 2), neither result restricts the functional form of the probability of loss. Our functional form $p=1 /(1+k e), k>0$ has two features. First, the odds against loss proportionally increase in effort (Note $k e=(1-p) / p$ ). Second, a simple solution can be derived for the risk-neutral optimal effort $e_{n}=1 / k$ and the size of loss $d=4 / k$.
} 


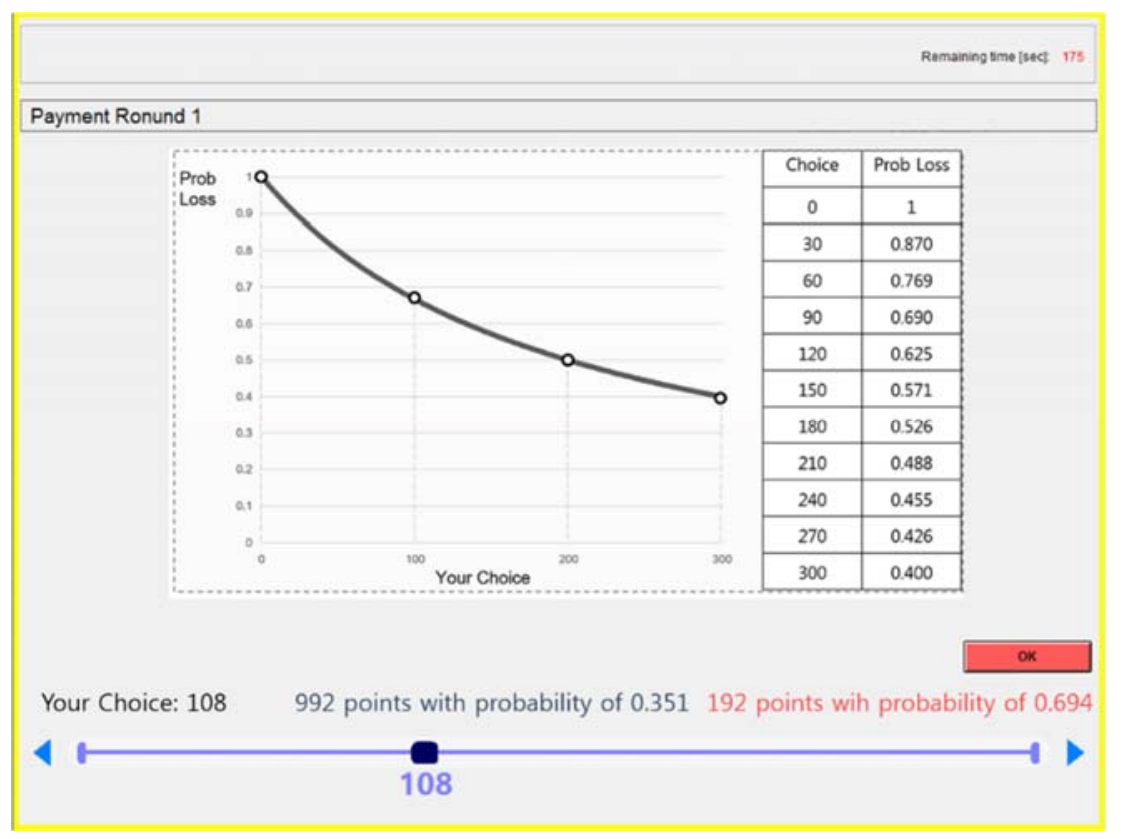

Fig. 3 Decision screen

We vary timing of loss as a treatment. Future loss $(\mathrm{F})$ is an occurrence of loss to be determined one week after the session, while current loss (C) is defined as an occurrence of loss determined within the session. In each round of the F treatment, subjects have 1100 ECUs today and an additional 1300 ECUs as one week later endowment, based on the assumptions of Proposition 1. In C treatment, subjects have only 1100 ECUs as their endowment today. Figure 4 summarizes the decision making process of $\mathrm{F}$ and $\mathrm{C}$ treatments, respectively. 
(a) F treatment

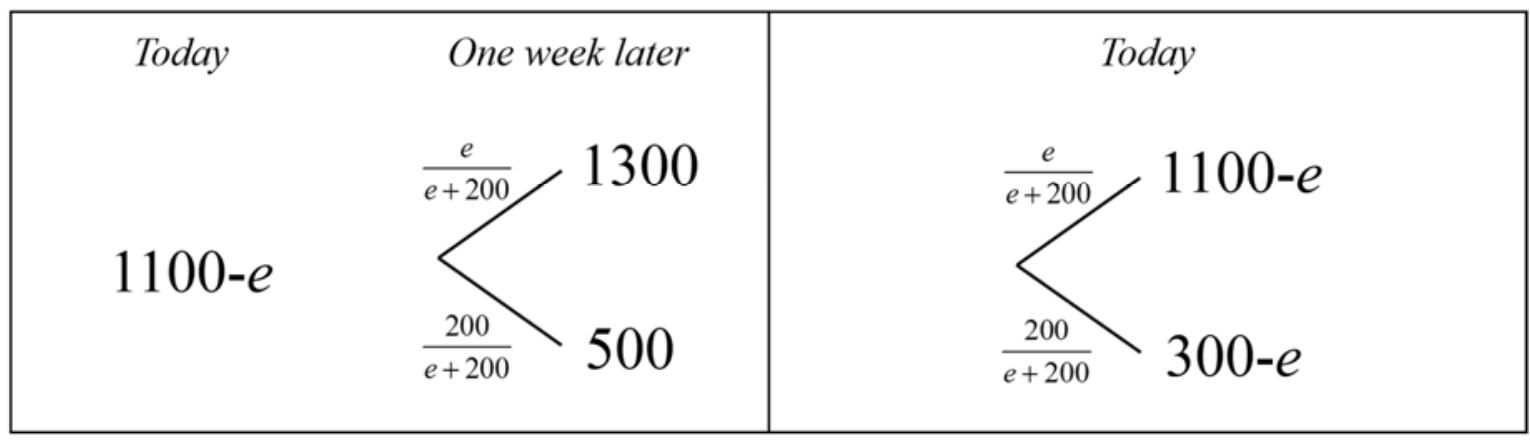

Fig. 4 Treatments in prevention game

In $\mathrm{F}$ treatment, subjects get feedback about certain today outcome and possible outcomes of one week later with the probability in each round. For example, if subjects choose 200 in F treatment, they will get feedback of 900 (today) and 1300 with probability of 0.5 or 500 with probability of 0.5 (one week later). In C treatment, subjects get feedback about possible outcomes for today with probability in each round. For example, if subjects select 200 in C treatment, they will have feedback of 900 with probability of 0.5 or 100 with probability of $0.5 .^{10}$ This feedback design is to avoid history dependent behavior about the realization of loss. At the end of the session, one of the 10 rounds is randomly selected for payment. In F treatment, subjects only know the probability of loss and possible outcome when the session ends. After one week, uncertainty is resolved, and they realize the exact payment. Subjects from F treatment are paid their today payment right after the session and one week later payment seven days after the session via bank transfer. In $\mathrm{C}$ treatment, uncertainty is resolved at the end of the session. Subjects are paid their exact payment right after the session. All subjects need to visit the lab only once, and hence there is no substantial difference in the opportunity cost of participating in the experiment under $\mathrm{F}$ or $\mathrm{C}$ treatments.

${ }_{10}$ We provide the screenshots for feedback depending on treatments in Online appendix A. 
Part 3 measures the time preferences of each individual. This is not considered in the theoretical model in Menegatti (2009); however, empirically, this issue could affect intertemporal choices. We elicit a switching point from a certain amount (1000 yen) today to varying amounts (from 1 yen to 1300 yen) one week later. We note that time discounting in this study refers to both present bias and time discounting. ${ }^{11}$ After finishing Part 3, the subjects completed a demographic questionnaire asking their age, gender, academic department, and years of study.

Table 3 summarizes the information from the sessions. Noussair et al. (2014) classify around $89 \%$ of subjects in the lab as prudent subjects. Based on their results, we expect effort to be greater than 200 in F treatment, while effort in $C$ treatment is expected to be less than 200. Individual payments ranged from $500 \mathrm{JPY}$ to 5,760 JPY, with no show up fee. The sessions lasted for 90 to 120 minutes.

Table 3. Summary of the sessions

\begin{tabular}{cccccc}
\hline Treatment & $\begin{array}{c}\text { Risk neutral } \\
\text { effort }\end{array}$ & $\begin{array}{c}\text { Prediction under } \\
\text { prudence }\end{array}$ & Sessions & $\begin{array}{c}\text { Subjects } \\
\text { per session }\end{array}$ & $\begin{array}{c}\text { Average } \\
\text { payment }\end{array}$ \\
\hline F & 200 & $e>200$ & $3(1)^{\mathrm{a}}$ & $20,19,(11)$ & $4380^{\mathrm{b}}$ \\
$\mathrm{C}$ & 200 & $e<200$ & $4(2)$ & $20,18,(18),(13)$ & 1860 \\
\hline
\end{tabular}

a) Statistics in parentheses represent the sessions at Seoul National University. b) Unit of payment is yen.

\section{Experimental Results}

\subsection{High order risk attitudes}

We investigate the summary statistics of prudence, risk aversion, and temperance. Prudence is measured as the number of prudent choices among 10 questions. We define risk aversion as the number of safe choices out of five choices, and measure temperance as the number of temperate

\footnotetext{
${ }^{11}$ In Online appendix, we explain the details of the process in Part 3 and its instructions.
} 
choices out of five answers. These variables are used also in regression afterward. In this subsection, results for non-parametric Mann Whitney test are reported in parenthesis. Figure 5 reports the histograms of the risk attitude traits of subjects. Regarding prudence, $60.5 \%$ of subjects have a score of 10, the maximum value of prudence. Additionally, $97.3 \%$ of subjects have a score of more than or equal to 5. This shows that there is little variance in prudence compared with riskaversion and temperance. This pattern is in line with Noussair et al. (2014), who find that about $70 \%$ of their lab participants have their maximum level of prudence. Gender difference in prudence is not significant; the average levels of prudence for males and females were 8.69 and 9.05 , respectively (z statistics:1.00, p-value: 0.32). This result is consistent with Noussair et al. (2014), who find no gender difference in prudence.

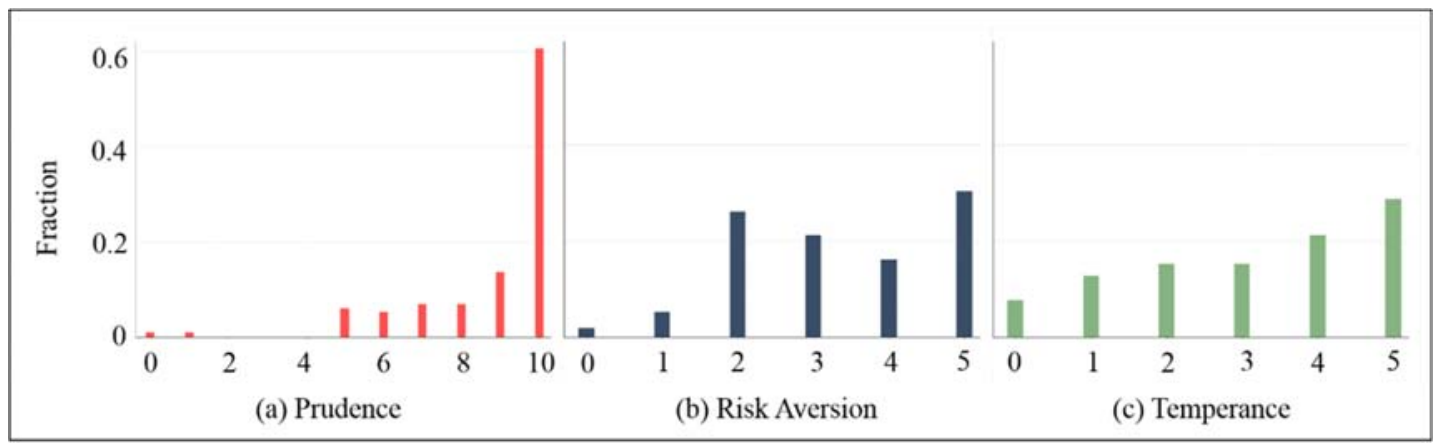

Fig. 5 Distribution of higher order risk attitudes

Risk aversion has a value between 0 and 5. On average, subjects score 3.35 in risk aversion, and $67.23 \%$ of subjects make risk averse choices more frequently; that is, with a score of 3 or more. Noussair et al. (2014) reported 3.60 as an average degree of risk aversion, which is slightly above our results. Deck and Schlesinger (2006) also reported that around $80 \%$ of subjects are risk averse, marginally above our results. Female and male subjects have average risk aversion scores of 3.95 
and 2.75, respectively. This difference is significant at the $1 \%$ level (z statistics: 4.78 , p-value < 0.01) and consistent with literature (Eckel and Grossman 2008; Ebert and Wiesen 2014; Noussair et al. 2014), which confirms that females are more likely to be risk-averse.

Lastly, temperance has a value between 0 and 5, with an average score of $3.15 ; 64.71 \%$ of the subjects have a tendency to choose the temperate option more frequently, with a score of 3 or more. We confirm that female subjects are likely to have higher temperance (3.55) than male subjects (2.74) on average. This difference is significant at the 5\% level (z statistic: $2.20, \mathrm{p}$-value: 0.02), and is consistent with previous literature, which reports a higher level of temperance in female subjects (Noussair et al. 2014; Ebert and Wiesen 2014).

Regarding correlation within higher order risk attitudes, the correlation of risk aversion and temperance is significant at the $1 \%$ level in Pearson pairwise correlation test, while no other relationship is significantly correlated at the $5 \%$ level. ${ }^{12}$ This pattern is similar to the results of Noussair et al. (2014) and Deck and Schlesinger (2014), which report positive correlation between risk aversion and temperance. This result implies that prudence captures different aspects with risk aversion and temperance.

\subsection{Effort in the prevention game}

Throughout this subsection, we used individual average effort for 10 rounds as a unit of observation (henceforth, average effort). Figure 6 shows the distribution of average effort by subjects across treatments. The mean of average effort in F (C) treatment is 182.8 (180.5). We used the Wilcoxon signed-rank test to test whether average effort is different from risk neutral effort. The average effort in F (z statistics: 1.68, p-value: 0.09 ) and C (z statistics: 2.31, p-value: 0.02)

${ }^{12}$ We also tested whether Osaka and Seoul subjects differ in risk attitudes, as reported in Online appendix B. There is no significant difference in risk attitudes between Osaka and Seoul subjects. 
treatments are significantly less than the risk neutral level of 200. Moreover, the difference in the average effort between $\mathrm{F}$ and $\mathrm{C}$ treatments is not significant at the $10 \%$ level based on the MannWhitney test (z statistics: 0.05, p-value: 0.96).

(a) F treatment

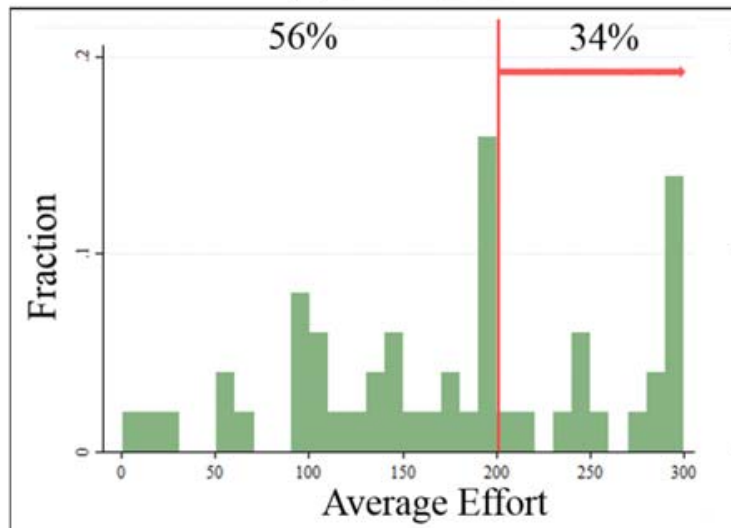

(b) C treatment

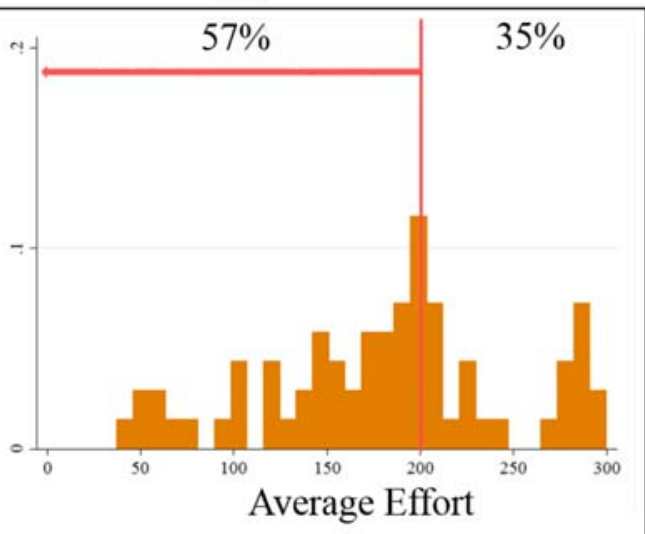

Notes. Vertical lines represent 200, which is the risk neutral bench mark. The percentage on the left (right) of the vertical line shows the proportion of average contribution less (greater) than 200 in each treatment. $10 \%(8 \%)$ of the subjects in F (C) treatment chose exactly 200 for 10 rounds. The horizontal arrow shows the area that is consistent with the theoretical predictions under prudence.

Fig. 6 Distribution of average effort across treatments

We show that more than $60 \%$ of subjects have a maximal prudent score and more than $97 \%$ of subjects tend to make the prudent choice more frequently, that is, with a score of 5 or more. Based on the theoretical predictions, we expect greater effort than 200 in F treatment, and less effort than 200 in C treatment than 200. However, the average effort in F treatment is less than the risk neutral level.

Result 1. Average effort is less than the risk neutral level, regardless of the timing of loss. 
We address the role of prudence within each treatment. Figure 7 shows the mean of average effort across the levels of prudence in each treatment. Both $\mathrm{F}$ and $\mathrm{C}$ treatments exhibit a negative correlation between average effort and prudence. In $\mathrm{F}$ treatment, subjects who have a prudence level equal to or less than 5 have a mean of average effort level around 270. However, those with a prudence level equal to 10 chose average effort around 160 . We measure the correlation between prudence and average effort using Pearson correlation test. The significantly negative correlation $(-0.38$, p-value $<0.01)$ contradicts the theoretical results of Menegatti (2009). In $\mathrm{C}$ treatment, when the level of prudence is equal to or less than 5, the average effort is around 261; however, when the level of prudence is 10 , the average prevention is around 169 . In $\mathrm{C}$ treatment, there is also negative correlation $(-0.36$, p-value $<0.01)$. This result is consistent with Eeckhoudt and Gollier (2005), who predict a negative correlation between prudence and effort.

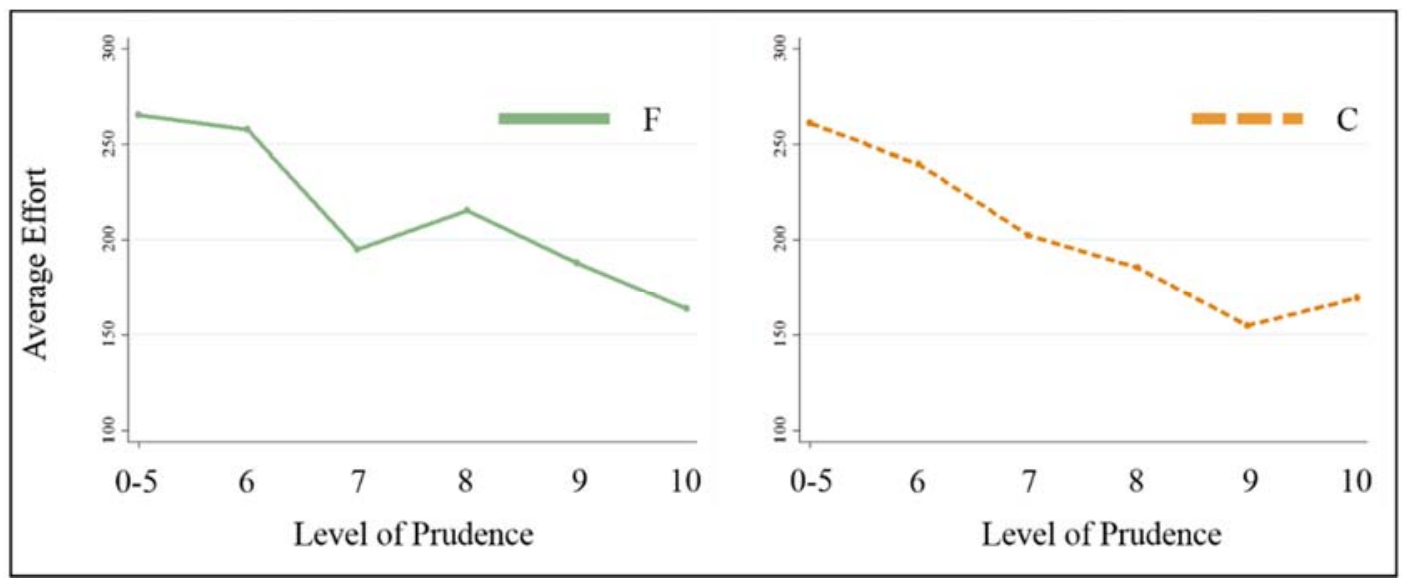

Fig. 7 Average effort across the level of prudence in $\mathrm{F}$ and $\mathrm{C}$ treatments

Result 2. There is a negative correlation between prudence and average effort for both $F$ and $C$ treatments. 
We conduct a regression analysis to check the robustness of prudence in average effort after controlling for other higher order risk attitudes and basic demographics. The linear regression specification is as follows.

$$
\begin{gathered}
\text { Average effort }_{i}=\beta_{0}+\beta_{1} \text { Prudence }_{i}+\beta_{2} \text { Aversion }_{i}+\beta_{3} \text { Temperance }_{i} \\
+\beta_{4} \text { Female }_{i}+\beta_{5} \text { Age }_{i}+\beta_{6} \text { Time discount }_{i}+\epsilon_{i}
\end{gathered}
$$

In the specification, subscript $i$ denotes individuals in the prevention game. We also include the individual characteristics of age, sex, and time discount. The time discount variable is the switching point of individuals between a certain amount today and a varying amount one week later, which has an observed range of 1000 to $1300 .{ }^{13}$ Higher values of this variable mean that the subjects discount the one week later payment more.

Table 4 shows the regression results using sub-samples corresponding to each treatment. Columns (1) and (2) show the regression results using the F treatment only. The coefficients on prudence (-14.91 and -13.39) are negative and significant at the $10 \%$ level, which contradicts the results of Menegatti (2009). In column (1), the coefficient of Aversion (-18.45) is negative and significant at the 5\% level. However, after controlling for demographics, the significance of Aversion disappears in column (2). Columns (3) and (4) report the regression results of C treatment, which also show a negative correlation between prudence and average effort (-10.54 and -11.01). Interestingly, the degree of risk aversion and temperance are not significantly correlated with average effort in columns (2) and (4), which corroborates the statements in the Propositions 1 and

\footnotetext{
${ }^{13}$ Instructions and an explanation of the time discount variable are in Online appendix A.
} 
2 that only prudence matters. ${ }^{14}$

Table 4. Impact of higher order risk attitudes on average effort

\begin{tabular}{|c|c|c|c|c|}
\hline Sample & $\begin{array}{c}F \\
(1)\end{array}$ & $\begin{array}{c}F \\
(2)\end{array}$ & $\begin{array}{c}\mathrm{C} \\
(3)\end{array}$ & $\begin{array}{c}\mathrm{C} \\
(4)\end{array}$ \\
\hline \multirow[t]{2}{*}{ Prudence } & $-14.91^{* * *}$ & $-13.39^{*}$ & $-10.54^{* *}$ & $-11.01^{* * *}$ \\
\hline & $(5.56)^{\mathrm{a}}$ & $(6.96)$ & $(4.34)$ & $(3.94)$ \\
\hline \multirow[t]{2}{*}{ Aversion } & $-18.45^{* *}$ & -6.07 & -5.03 & -0.46 \\
\hline & $(8.87)$ & $(8.59)$ & $(5.37)$ & $(6.62)$ \\
\hline \multirow[t]{2}{*}{ Temperance } & 3.13 & 3.26 & 1.27 & 2.94 \\
\hline & $(7.63)$ & $(6.16)$ & $(4.77)$ & $(4.76)$ \\
\hline \multirow[t]{2}{*}{ Female } & & $-77.56^{* * *}$ & & -3.37 \\
\hline & & $(21.95)$ & & (19.49) \\
\hline \multirow[t]{2}{*}{ Age } & & -0.06 & & $7.74^{* *}$ \\
\hline & & $(1.77)$ & & $(3.26)$ \\
\hline \multirow[t]{2}{*}{ Time discount } & & -0.17 & & $0.13^{* *}$ \\
\hline & & $(0.12)$ & & $(0.06)$ \\
\hline \multirow[t]{2}{*}{ Seoul session } & 6.43 & 9.78 & 8.35 & -11.36 \\
\hline & $(28.26)$ & $(23.35)$ & $(15.92)$ & $(18.47)$ \\
\hline \multirow[t]{2}{*}{ Constant } & $366.59^{* * *}$ & $533.74^{* * *}$ & $282.37^{* * *}$ & -45.37 \\
\hline & $(44.72)$ & $(127.82)$ & $(45.67)$ & $(95.03)$ \\
\hline
\end{tabular}

$\begin{array}{lllll}\text { Observations } & 50 & 50 & 69 & 69\end{array}$

$\begin{array}{lllll}\text { R-squared } & 0.22 & 0.41 & 0.14 & 0.23\end{array}$

Notes. Significance levels $* * * / * * *$ represent $10 \%, 5 \%$, and $1 \%$, respectively. a) Robust standard errors in parentheses.

${ }^{14}$ Regarding the time discount variable, subjects who discount more have a tendency to exert more effort in $\mathrm{C}$ treatment, although the mechanism is unclear because $\mathrm{C}$ treatment is not an intertemporal choice problem. 
Although our results show a consistent negative pattern in $\mathrm{F}$ and $\mathrm{C}$ treatments, there are possibly some issues. First, F treatment may not be recognized by subjects as two distinctive periods, as presented in the theoretical model. If they recognize $\mathrm{F}$ treatment as one period, then theoretically $\mathrm{F}$ treatment is identical to the problem in $\mathrm{C}$ treatment. However, using our time discounting data in Part 3, we confirm that subjects on average discount the one week later monetary outcome by $5 \%$. This amount of discounting is significantly different from no discounting based on the Wilcoxon signed-rank test. Therefore, it is natural to use a payoff separable model in F treatment because there is time discounting. The second issue is that the role of time discounting is not theoretically considered in Menegatti (2009). In Online appendix C, we again compute the risk neutral benchmark at the individual level considering the degree of individuals' time discounting. We compare average effort with this newly computed risk neutral benchmark after considering time discounting. We still find that more than $50 \%$ of subjects in $\mathrm{F}$ treatment contribute less than the risk neutral level of effort even after considering time discounting. ${ }^{15}$ Finally, Peter (2017) find a negative correlation between prudence and prevention in a two period model when subjects can transfer their income from the first period to the second period. Even though Peter's (2017) argument is not testable in our design, this result could possibly suggest the mechanism behind our results.

\section{Alternative Explanation: Probability Weighting}

In Part 2, our subjects exert less effort than the risk neutral level in both the current and future loss treatments, while they chose prudent options in Part 1. These observations contradict

\footnotetext{
${ }^{15}$ Online appendix $\mathrm{C}$ reports the distribution for our elicited time preference and how the risk neutral level was recomputed considering time preference. We also confirm that Menegatti's (2009) theoretical result holds after considering time discounting.
} 
the predictions of expected utility. Eeckhoudt et al. (2017) provide the counterpart of prudence, as described in expected utility, using probability weighting. Their result implies that expected utility is too narrow to describe prudent behavior. In the same spirit, we introduce probability weighting to explain our observations in a uniform way. Probability weighting describes an individual's inability to sufficiently discriminate changes in probability. We found that i) a player with probability weighting will choose an optimal effort lower than that of a risk-neutral player, regardless of the timing of the loss; and ii) probability weighting explains why a large portion of subjects chose prudent options in our elicitation task. Together, these two results explain our observations of high prudence and prevention effort below the risk neutral level. We note that our experimental design is not capable of testing the role of probability weighting in prevention. What we present is one of the possible mechanisms that cannot be explained in expected utility.

For a clear argument, we focus on common functional forms. Consider a binary lottery $(a, p ; b)$. We use Prelec (1998) weighting function

$$
w^{\gamma}(p)=\exp \left(-(-\ln p)^{\gamma}\right), 0<\gamma \leq 1,
$$

for any probability $0 \leq p \leq 1$. Note that the probability of a bad outcome $(b)$ is distorted as $1-w^{\gamma}(p)$. The parameter $\gamma$ determines the inverse-S shape of probability weighting. As $\gamma$ is closer to zero, the probability distortion is more severe. The case of $\gamma=1$ is the same as expected utility. We note that for any $\gamma$, the fixed point is around $(0.37,0.37) .{ }^{16}$ We assume the linear utility about monetary outcome because curvature of monetary outcome also affects risk attitudes. ${ }^{17}$ We try to exclude the effect of utility curvature and only explain the mechanism through probability weighting.

\footnotetext{
${ }^{16}$ See Stott (2006) and Schmidt et al. (2008) for existing variations of the value and probability weighting functions.

${ }^{17}$ Eeckhoudt et al. (2017) also assume linear utility.
} 
We consider a $\gamma$-Prelec player who evaluates a binary lottery $L=(a, p ; b)$ with $a>b$ as $V(L ; \gamma):=w^{\gamma}(p) a+\left\{1-w^{\gamma}(p)\right\} v b$ where $w$ is given by (7). Consider the prevention game with future loss by a $\gamma$-Prelec player. The player maximizes $(y-e)+V((z, 1-p(e) ; z-d) ; \gamma)$. On the other hand, in a game with a current loss, a Prelec player maximizes $V((y-e, 1-p(e) ; y-e-d) ; \gamma)$. The next proposition states probability weighting players exerts low efforts, as observed in our experiment. Let e denote Napier's constant.

Proposition 3. i) Consider a prevention game with future loss where, z satisfies (4) and $p(e)=1 /(1+k e), k>0$. Then, for any $\gamma \in(0,1]$, a $\gamma$-Prelec player exerts less effort than a risk neutral player. ii) Consider the prevention game with current loss where $p(e)=1 /(1+k e), k>0$. Then, for any $\gamma \in(0,1]$, a $\gamma$-Prelec player exerts less effort than a risk neutral player.

Proof. See Appendix.\|

To close this section, we show that a Prelec player also chooses the prudent option in our Part 1 task. Together with Propositions 3 and 4, this shows that Prelec's weighting provides a unified explanation of high prudence and low effort regardless of the loss timing. The value $V(L)$ of a three-outcome lottery $L=\left(x_{1}, p_{1} ; x_{2}, p_{2} ; x_{3}\right) \quad$ with $x_{1}>x_{2}>x_{3} \quad$ is $V(L)=w\left(p_{1}\right) x_{1}+\left\{w\left(p_{1}+p_{2}\right)-w\left(p_{1}\right)\right\} x_{2}+\left\{1-w\left(p_{1}+p_{2}\right)\right\} x_{3}$.

Observation. For any $\gamma \in(0,1]$, a $\gamma$-Prelec player prefers the prudent option in any question in our prudence elicitation task.

Proof. See Appendix.\| 


\section{Conclusions}

This study uses different timings of loss to test on the role of prudence in prevention because theoretical predictions of prudence drastically change depending on the timing of the outcomes. We find that prudence is strongly correlated with self-protection behavior in our prevention games. However, in contrast to theoretical predictions, prudence is negatively associated with prevention in both timings of loss. This result implies the importance of prudence in prevention decisions; however, the mechanism could be different from what is suggested by the expected utility model. We propose the alternative explanation using probability weighting to accommodate the results of the experiment. Like this paper, one avenue for future work is understanding the mechanisms underlying prudence and various types of economic decision making. As Eeckhoudt et al. (2017) suggest, different definitions of prudence using probability weighting instead of the expected utility model could be helpful in understanding the role of prudence in economic decision.

\section{Appendix A. Proofs}

Proof of Proposition 3. i) Future loss. Take any $\gamma \in(0,1]$. An $\gamma$-Prelec player chooses effort $e$ to maximize

$$
y-e+w^{\gamma}(q) z+\left(1-w^{\gamma}(q)\right)(z-d) \equiv P^{f, \gamma}(e),
$$

where $q=q(e)=1-p(e)=k e /(1+k e)$. First, we check the first order condition.

$$
\frac{d P^{f, \gamma}}{d e}=-1+d \frac{d w^{\gamma}}{d q} \frac{d q}{d e}
$$

By substituting $d w^{\gamma} / d q=\left(\gamma(-\ln q)^{\gamma-1} / q\right) \cdot w^{\gamma}(q), \quad p\left(e_{n}\right)=1 / 2$, and $-p^{\prime}\left(e_{n}\right)=1 / d$,

$$
\begin{aligned}
\left.\frac{d P^{f, \gamma}}{d e}\right|_{e=e_{n}} & =-1+d \cdot \gamma \frac{(-\ln (1 / 2))^{\gamma-1}}{1 / 2} \cdot w^{\gamma}(1 / 2) \cdot \frac{1}{d} \\
& =-1+\cdot 2 \gamma(\ln 2)^{\gamma-1} \cdot \exp \left(-(\ln 2)^{\gamma}\right)
\end{aligned}
$$


Since

$$
\frac{d}{d \gamma}\left\{\gamma(\ln 2)^{\gamma-1} \cdot \exp \left(-(\ln 2)^{\gamma-1}\right\}=\exp \left(-(\ln 2)^{\gamma}\right)(\ln 2)^{-1+\gamma}\left(2-2 \gamma\left(-1+(\ln 2)^{\gamma}\right) \ln (\ln 2)\right)>0\right.
$$

by $0<\gamma \leq 1,0<(\ln 2)^{\gamma} \leq 1$ and $-1<\ln (\ln 2)<0$, we have

$$
\left.\frac{d P^{f, \gamma}}{d e}\right|_{e=e_{n}} \leq\left.\frac{d P^{f, 1}}{d e}\right|_{e=e_{n}}=0 \text { for any } \gamma \in(0,1) \text {. }
$$

Second, we check the second order condition. Since

$$
\frac{d^{2} P^{f, \gamma}}{d e^{2}}=\frac{d \cdot \exp \left(-(-\ln q)^{\gamma}\right) \gamma(-\ln q)^{-2+\gamma}\left(1+\gamma\left(-1+(-\ln q)^{\gamma}\right)+(1+2 k e) \ln q\right)}{e^{2}(1+e k)^{2}}
$$

and $\mathrm{ke}=\mathrm{q} /(1-\mathrm{q})$, it suffices to show

$$
h(q, \gamma)=1+\gamma\left(-1+(-\ln q)^{\gamma}\right)+\frac{1+q}{1-q} \ln q \leq 0 \text { for all } q \in(0,1] \text { and } \gamma \in(0,1] \text {. }
$$

Let e be Napier's constant.

Case 1. $q \in\left(0, \mathbf{e}^{-1}\right]$

Since

$$
\frac{\partial h}{\partial \gamma}(q, \gamma)=-1+(-\ln q)^{\gamma}+\gamma(-\ln q)^{\gamma} \ln (-\ln q) \geq 0 \text { for all } q \in\left(0, q^{*}\right],
$$

$h(q, \gamma) \leq h(q, 1)=2 q \ln q /(1-q)$ for all $q \in\left(0, \mathbf{e}^{-1}\right]$ and $\gamma \in(0,1]$. Hence,

$h(q, \gamma) \leq h(q, 1)<\lim _{q \rightarrow 0} h(q, 1)=\lim _{q \rightarrow 0} \frac{2 q \ln q}{1-q}=2 \cdot 1 \cdot \lim _{q \rightarrow 0} q \ln q=2 \cdot\left(-\lim _{r \rightarrow \infty} \frac{\ln r}{r}\right)=0$ for all $q \in\left(0, q^{*}\right]$ and $\gamma \in(0,1]$.

Case 2. $q \in\left(\mathbf{e}^{-1}, 1\right]$

Since

$$
\frac{\partial h}{\partial \gamma}(q, \gamma)<0 \text { for all } q \in\left[q^{*}, 1\right]
$$

$h(q, \gamma) \leq h(q, 0)=1+\frac{1+q}{1-q} \ln q$ for all $q \in\left(\mathbf{e}^{-1}, 1\right]$ and $\gamma \in(0,1]$. Hence,

$h(q, \gamma) \leq h(q, 0) \leq \lim _{q \rightarrow 1} h(q, 0)=1+\lim _{q \rightarrow 1} \frac{1+q}{1-q} \ln q=1-\lim _{q \rightarrow 1}(1+q) \lim _{s \rightarrow 0} \frac{\ln (s+1)}{s}=1-2=-1$.

Hence, the objective function is concave.

ii) Current loss. The same argument holds by linearity of valuation function of money. ॥

\section{Proof of observation.}

Take any a, b, z with a $>$ b. $L=(a, .50 ; b+z, .25 ; b-z), R=(a+z, .25 ; a-z, .25 ; b)$. 
Suppose $a>b+z$.

$V(R)=w(.25)(a+z)+\{w(.5)-w(.25)\}(a-z)+\{w(1)-w(.5)\} b$

$V(L)=w(.5) a+\{w(.75)-w(5)\}(b+z)+\{w(1)-w(.75)\}(b-z)$

Then,

$$
\begin{aligned}
V(R)-V(L)= & w(.25)\{(a+z)-(a-z)\}+w(.5)\{(a-z)-b-a+(b+z)\} \\
& +w(.75)\{(b-z)-(b+z)\}+w(1)\{b-(b-z)\} \\
= & (2 w(.25)-2 w(.75)+1) z \geq 0 .
\end{aligned}
$$

The last inequality holds by $w(.75)-w(.25) \leq 0.5$ for any Prelec function.

Suppose next $a<b+z$.

$V(R)=w(.25)(a+z)+\{w(.75)-w(.25)\} b+\{w(1)-w(.75)\}(a-z)$

$V(L)=w(.25)(b+z)+\{w(.75)-w(.25)\} a+\{w(1)-w(.75)\}(b-z)$

Then,

$$
\begin{aligned}
V(R)-V(L)= & w(.25)\{(a+z)-(b+z)-(b-a)\}+w(.75)\{b-(a-z)-a+(b-z)\} \\
& +w(1)\{(a-z)-(b-z)\} \\
= & (2 w(.25)-2 w(.75)+1)(a-b) \geq 0 .
\end{aligned}
$$

The last inequality holds by $w(.75)-w(.25) \leq 0.5$ for any Prelec function. $\|$

Acknowledgements: We sincerely thank Charles Noussair for his continuous encouragement and helpful suggestions, which significantly improved the paper. We thank Soo Hong Chew, Syngjoo Choi, Nobuyuki Hanaki, Stefan Trautmann, Songfa Zhong, the participants of 2017 the ESA North American Meeting, the University of Arizona experimental reading group, and the SURE workshop at Seoul National University. Sebastian Ebert kindly shared with us their z-Tree programs. Masuda completed most of this study during his visit to the Economic Science Laboratory at the University of Arizona. Financial support by JSPS KAKENHI Grant Number 17K13701, 15H05728, the Keihanshin Consortium for Fostering the Next Generation of Global Leaders in Research (K-CONNEX), the John-Mung Overseas Program, and the Murata Science Foundation are gratefully acknowledged. Lee acknowledges funding from the BK21Plus Program of the Ministry of Education and National Research Foundation of Korea (NRF-21B20130000013). 


\section{References}

Bleichrodt, H., \& van Bruggen, P. (2018). Higher order risk preferences for gains and losses. Working Paper.

Cardella, E., \& Kitchens, C. (2017). The impact of award uncertainty on settlement negotiations. Experimental Economics, 20(2), 333-367.

Courbage, C., Rey, B., \& Treich, N. (2013). Prevention and precaution. Handbook of Insurance, 185-204. New York, NY: Springer.

Deck, C., \& Schlesinger, H. (2010). Exploring higher order risk effects. The Review of Economic Studies, 77(4), 1403-1420.

Deck, C., \& Schlesinger, H. (2014). Consistency of higher order risk preferences. Econometrica, 82(5), 1913-1943.

Ebert, S., \& Wiesen, D. (2011). Testing for prudence and skewness seeking. Management Science, 57(7), 1334-1349.

Ebert, S., \& Wiesen, D. (2014). Joint measurement of risk aversion, prudence, and temperance. Journal of Risk and Uncertainty, 48(3), 231-252.

Eckel, C. C., \& Grossman, P. J. (2008). Men, women and risk aversion: Experimental evidence. Handbook of Experimental Economics Results, 1, 1061-1073.

Eeckhoudt, L., \& Gollier, C. (2005). The impact of prudence on optimal prevention. Economic Theory, 26(4), 989-994.

Eeckhoudt, L. R., Laeven, R. J. A., \& Schlesinger, H. (2017). Risk Apportionment: The Dual Story. arXiv preprint arXiv:1712.02182.

Eeckhoudt, L., \& Schlesinger, H. (2006). Putting risk in its proper place. The American Economic Review, 96(1), 280-289.

Fischbacher, U. (2007). z-Tree: Zurich toolbox for ready-made economic experiments. Experimental Economics, 10(2), 171-178. 
Gollier, C. (2004). The Economics of Risk and Time. MIT press.

Gollier, C., Hammitt, J. K., \& Treich, N. (2013). Risk and choice: A research saga. Journal of Risk and Uncertainty, 47(2), 129-145.

Gollier, C., Jullien, B., \& Treich, N. (2000). Scientific progress and irreversibility: an economic interpretation of the 'Precautionary Principle.' Journal of Public Economics, 75(2), 229253.

Greiner, B. (2015). Subject pool recruitment procedures: Organizing experiments with ORSEE. Journal of the Economic Science Association, 1(1), 114-125.

Haering, A., Heinrich, T., \& Mayrhofer, T. (2017). Exploring the consistency of higher-order risk preferences (No. 688). Ruhr Economic Papers.

Heinrich, T., \& Mayrhofer, T. (2018). Higher-order risk preferences in social settings. Experimental Economics, 21(2), 434-45

Kahneman, D., \& Tversky, A. (1979). Prospect theory: An analysis of decision under risk. Econometrica, 263-291.

Kimball, M. S. (1990). Precautionary saving in the small and in the large. Econometrica, 53-73.

Kocher, M. G., Pahlke, J., \& Trautmann, S. T. (2015). An experimental study of precautionary bidding. European Economic Review, 78, 27-38.

Krieger, M., \& Mayrhofer, T. (2017). Prudence and prevention: An economic laboratory experiment. Applied Economics Letters, 24(1), 19-24.

Leland, H. E. (1968). Saving and uncertainty: The precautionary demand for saving. The Quarterly Journal of Economics, 82(3), 465-473.

Menegatti, M. (2009). Optimal prevention and prudence in a two-period model. Mathematical Social Sciences, 58(3), 393-397.

Noussair, C. N., Trautmann, S. T., \& van de Kuilen, G. (2014). Higher order risk attitudes, demographics, and financial decisions. Review of Economic Studies, 81(1), 325-355.

Peter, R. (2017). Optimal self-protection in two periods: On the role of endogenous saving. Journal of Economic Behavior \& Organization, 137, 19-36. 
Prelec, D. (1998). The probability weighting function. Econometrica, 497-527.

Schmidt, U., Starmer, C., \& Sugden, R. (2008). Third-generation prospect theory. Journal of Risk and Uncertainty, 36(3), 203.

Stott, H. P. (2006). Cumulative prospect theory's functional menagerie. Journal of Risk and Uncertainty, 32(2), 101-130.

Trautmann, S. T., \& van de Kuilen, G. (2018). Higher order risk attitudes: A review of experimental evidence. European Economic Review, 103, 108-124.

Tversky, A., \& Kahneman, D. (1992). Advances in prospect theory: Cumulative representation of uncertainty. Journal of Risk and Uncertainty, 5(4), 297-323.

Wakker, P. P. (2010). Prospect Theory: For Risk and Ambiguity: Cambridge University Press.

White, L. (2008). Prudence in bargaining: The effect of uncertainty on bargaining outcomes. Games and Economic Behavior, 62(1), 211-231. 